\title{
Analysis of Vibration Characteristics for a Rotor-Bearing System Using Distributed Spring and Damper Model
}

\author{
D. C. HAN, S. H. CHOI and Y. H. LEE \\ Department of Mechanical Design and Production Engineering, College of Engineering, Seoul National University, San 56-1, \\ Shinlim-Dong, Kwanak-Gu, Seoul, 151-742, Korea
}

\begin{abstract}
In this paper, we modelled the journal bearings as distributed springs and dampers to investigate the influence of bearing width on the vibration characteristics of a rotor-bearing system. A quadratic function is used as a shape function for hydrodynamic journal bearings. And a trapezoidally or a quadratically distributed model is used as a shape function for hydrostatic journal bearings. A finite element method is applied for analyzing the vibration characteristics of a rotor-bearing system.

Dimensionless governing equations are derived for a uniform rotor supported by two journal bearings, which are modelled as point supported or distributed springs and dampers. For these models, natural frequencies for various bearing length ratios and stiffness ratios between the bearing and the shaft are calculated and compared with each other. Then the stability limits of a rotor supported by two cylindrical journal bearings are calculated for the point supported or distributed springs and dampers.
\end{abstract}

Key Words: Natural Frequency; Vibration; Bearing Width; Journal Bearing; Length Ratio

\section{INTRODUCTION}

A t present, the development of turbomachinery tends to increase the rotating speed for the purpose of decreasing the weight to power ratio of machines. So, the vibration is one of the most important problems to be solved. In analyzing the dynamic behavior of rotorbearing systems, various mathematical models have been developed and used over the past few decades. A finite element approach is one of the most widely used methods for this purpose.

In the early finite element investigations, many effective models considering gyroscopic effect, axial force, torque, internal viscous damping, internal hysteretic damping and shear effects for uniform or tapered shafts were developed by Nelson [1980], Özguven and Özkan [1984], Rouch and Kao [1979], and Gmür and Rodrigues [1991]. The bearings were simplified as point supported or uniformly distributed springs and dampers by Mourelatos and Parsons [1987]. It is a reasonable assumption when using ball bearings or short width journal bearings.
However, in the case of a long width journal bearing the pressure created in journal is different along the axial direction as well as radial direction. So, when the bearing width increases for the sake of large bearing load capacity, the bearing force is no more a point force. The pressure distribution in axial direction of a hydrodynamic journal bearing is quadratic function or trapezoidal function for a hydrostatic journal bearing.

In the present study, journal bearings are modelled as quadratically and trapezoidally distributed springs and dampers along the shaft. For these models natural frequencies for various design parameters are calculated and compared to each other. And the stability limits of the rotating speed are calculated for an example rotor using two types of support model.

\section{MODELING AND GOVERNING EQUATIONS}

The finite element equation for a typical rotor-bearing system can be written as 
$[\mathrm{M}]\{\ddot{\mathrm{q}}\}+\left(\left[\mathrm{C}_{\mathrm{B}}\right]-\Omega[\mathrm{G}]\right)\{\dot{\mathrm{q}}\}+\left(\left[\mathrm{K}_{\mathrm{B}}\right]+[\mathrm{K}]\right)\{\mathrm{q}\}=\{\mathrm{f}\}$

where subscript, B, denotes the bearing element.

The stiffness and damping matrices of a bearing, shown in FIGURE 1, can be written as

$\left[K_{B}^{e}\right]=J_{0}^{1}[\psi]^{T}\left[\begin{array}{ll}k_{y y}(s) & k_{y z}(s) \\ k_{z y}(s) & k_{z z}(s)\end{array}\right][\psi] d s$

$\left[C_{B}^{e}\right]=J_{0}^{1}[\psi]^{T}\left[\begin{array}{ll}c_{y y}(s) & c_{y z}(s) \\ c_{z y}(s) & c_{z z}(s)\end{array}\right][\psi] d s$

where s denotes an axial distance along element and [y] the matrix of the translational displacement shape function of a finite shaft element defined by equation (3),

$$
\{\mathrm{VW}\}^{\mathrm{T}}=[\Psi]\left\{\mathrm{q}_{1} \mathrm{q}_{2} \mathrm{q}_{3} \mathrm{q}_{4} \mathrm{q}_{5} \mathrm{q}_{6} \mathrm{q}_{7} \mathrm{q}_{8}\right\}^{\mathrm{T}}
$$

Shape functions, $k_{i j}$ and $c_{i j}$, were assumed as Dirac delta function(assumed a bearing as point supported one) or constant value(assumed as uniformly distributed one). However, a typical bearing analysis shows that the distribution shapes of springs and dampers are different from those assumptions.

FIGURE 2 and FIGURE 3 show the shapes of dynamic coefficients of typical hydrodynamic and twoline feed hydrostatic journal bearings, respectively. We approximate these shape functions as quadratic or trapezoidal functions, which are shown in FIGURE 4. These approximated shapes are shown by dashed lines in FIGURE 2 and FIGURE 3.

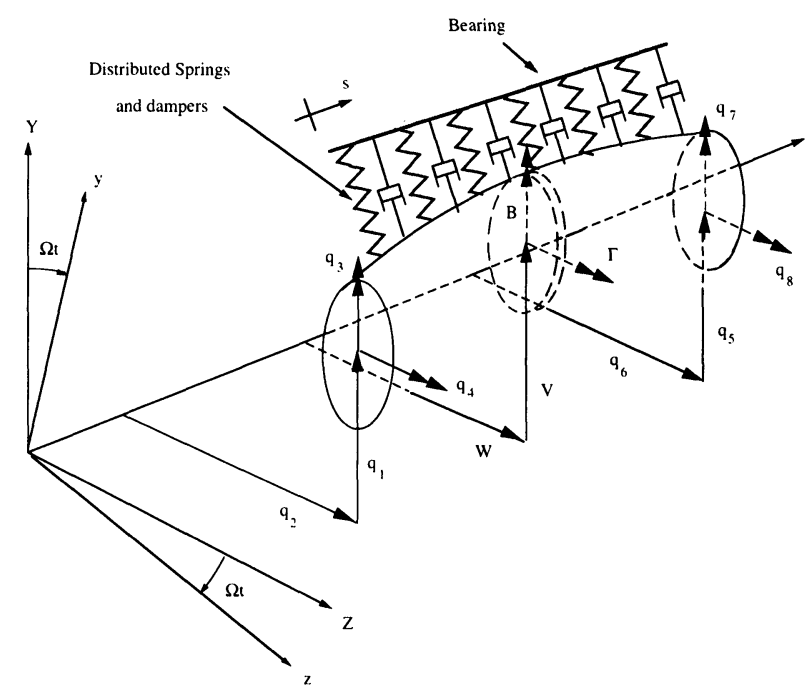

FIGURE 1 Finite shaft element in a bearing.
From these approximated shape functions we can rewrite equation (2) as

$\left[\mathrm{K}_{\mathrm{B}}^{\mathrm{e}}\right]=J_{0}^{1}[\psi]^{\mathrm{T}}\left[\begin{array}{ll}\mathrm{K}_{\mathrm{yy}} \mathrm{f}_{\mathrm{i}}(\mathrm{s}) & \mathrm{K}_{\mathrm{yz}} \mathrm{f}_{\mathrm{i}}(\mathrm{s}) \\ \mathrm{K}_{z y} \mathrm{f}_{\mathrm{i}}(\mathrm{s}) & \mathrm{K}_{z z} \mathrm{f}_{\mathrm{i}}(\mathrm{s})\end{array}\right][\psi] \mathrm{ds}$

$\left[C_{B}^{e}\right]=J_{0}^{1}[\psi]^{T}\left[\begin{array}{ll}C_{y y} f_{i}(s) & C_{y z} f_{i}(s) \\ C_{z y} f_{i}(s) & C_{z z} f_{i}(s)\end{array}\right][\psi] d s$

where $\mathrm{i}=0,1$, and 2 represent point supported, uniformly and quadratically distributed models, respectively.

For a two-line feed hydrodynamic bearing we can rewrite equation (2) as follows.

$\left[\mathrm{K}_{\mathrm{B}}^{\mathrm{e}}\right]=J_{0}^{1}[\psi]^{\mathrm{T}}\left[\begin{array}{cc}\mathrm{K}_{\mathrm{yy}} \mathrm{f}_{3}(\mathrm{~s}) & \mathrm{K}_{\mathrm{yz}} \mathrm{f}_{2}(\mathrm{~s}) \\ \mathrm{K}_{\mathrm{zy}} \mathrm{f}_{2}(\mathrm{~s}) & \mathrm{K}_{\mathrm{zz}} \mathrm{f}_{3}(\mathrm{~s})\end{array}\right][\psi] \mathrm{ds}$

$\left[C_{B}^{e}\right]=J_{0}^{1}[\psi]^{T}\left[\begin{array}{ll}C_{y y} f_{2}(s) & C_{y z} f_{2}(s) \\ C_{z y} f_{2}(s) & C_{z z} f_{2}(s)\end{array}\right][\psi] d s$

The shape functions, $f_{i}$, are given in APPENDIX.

\section{NONDIMENSIONALIZATION}

In this study, we consider the uniform shaft supported by two journal bearings as in FIGURE 5 to estimate the effects of bearing width on vibration characteristics. The governing equations of this system are given by equation (1).

The equations of this model shown in FIGURE 5 can be rewritten by using the following dimensionless quantities

$\bar{y}=y / L, \bar{z}=z / L, t=\omega_{0} t$

where $\omega_{0}$ is the first natural frequency of a simply supported Euler beam as

$\omega_{0}=\pi^{2} \sqrt{\frac{E I}{m^{4}}}$

Then, using the parameters in equation (6) the nondimensionalized equations are derived as

$[\overline{\mathrm{M}}][\ddot{\overline{\mathrm{q}}}\}+\left|\left[\overline{\mathrm{C}}_{\mathrm{B}}\right]-\frac{\Omega}{\omega_{0}}[\overline{\mathrm{G}}]\right|\{\dot{\overline{\mathrm{q}}}\}+\left(\left[\overline{\mathrm{K}}_{\mathrm{B}}\right]+\{\overline{\mathrm{K}}]\right)\{\overline{\mathrm{q}}\}=\{\overline{\mathrm{f}}\}$.

The generalized eigenvalue problem can be carried out, after rearranging equation (8) into a system of first order differential equations of the form 


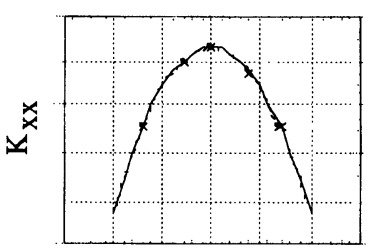

Axial distance

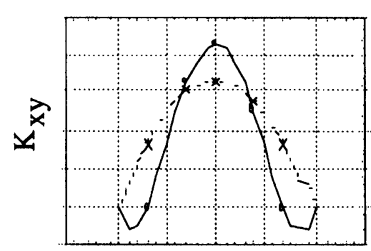

Axial distance

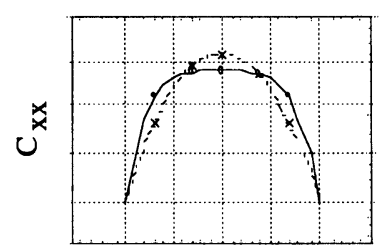

Axial distance

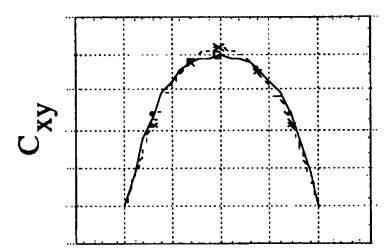

Axial distance

approximated

FIGURE 2 Distribution shapes of spring and damping coefficients for hydrodynamic bearing.

$[\mathrm{A}]\left\{\begin{array}{c}\ddot{\overline{\mathrm{q}}} \\ \dot{\overline{\mathrm{q}}}\end{array}\right\}+[\mathrm{B}]\left\{\begin{array}{l}\dot{\overline{\mathrm{q}}} \\ \overline{\mathrm{q}}\end{array}\right\}=\{\mathrm{F}\}$

where

$$
\begin{aligned}
& {[\mathrm{A}]=\left[\begin{array}{cc}
\frac{0}{[\overline{\mathrm{M}}]}[\overline{\mathrm{M}}] & 0
\end{array}\right],[\mathrm{B}]}
\end{aligned}
$$

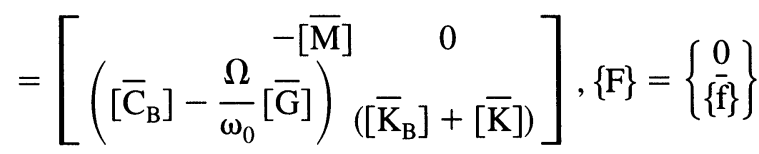

The damped natural frequencies of the system are then obtained by finding the eigenvalues of the dynamic matrix [D] which is given by

$[D]=[A]^{-1}[B]$

\section{NUMERICAL EXAMPLES AND RESULTS}

\section{Example 1}

In order to investigate the various effects of the rotorbearing system on the natural frequencies, we use four different models. They are models supported by point, by uniform pressure, quadratically and trapezoidally distrib(9) uted pressure over the length of the bearing, respectively. From the earlier analyses of bearings, we can approximate the magnetic bearings by uniformly distributed model, the hydrodynamic journal bearings by quadratically distributed model and the two-line feed hydrostatic journal bearings by hybrid model, that is, uncoupled springs are approximated by trapezoidally distributed and coupled springs and all dampers are approximated by quadratically distributed model. We use 9 shaft elements in point supported model and 8 elements in other models. All damping coefficients and the coupled terms of spring coefficients are set to zero and the uncoupled terms of spring coefficients are set by

$$
\begin{aligned}
& \mathrm{C}_{y y}=\mathrm{C}_{z z}=\mathrm{C}_{y z}=\mathrm{C}_{z y}=\mathrm{K}_{y z}=\mathrm{K}_{z y}=0 \\
& \mathrm{~K}_{y y}=\mathrm{K}_{z z}=\mathrm{K}_{\mathrm{B}}
\end{aligned}
$$

Other data for these cases are shown in TABLE 1.

We calculate the first two natural frequencies of the system varying bearing length ratio(B/L) for two different values of $B / L$. These results are shown in FIGUREs 6 and 7. Because the deflection shape of the shaft between the nodes is approximated by cubic function in finite element modeling, the stiffness of the distributed

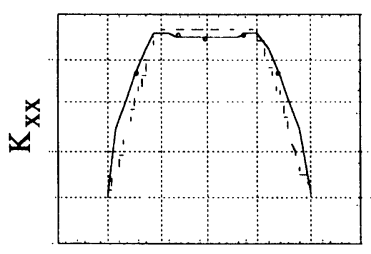

Axial distance

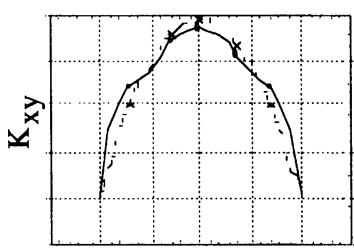

Axial distance

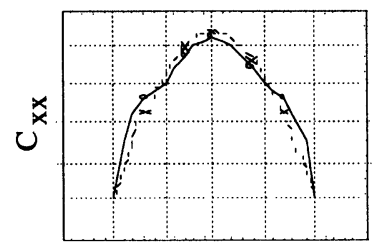

Axial distance

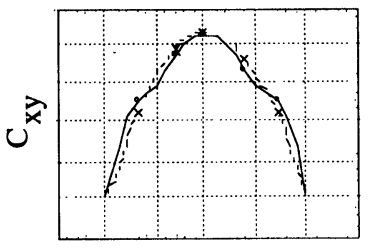

Axial distance 


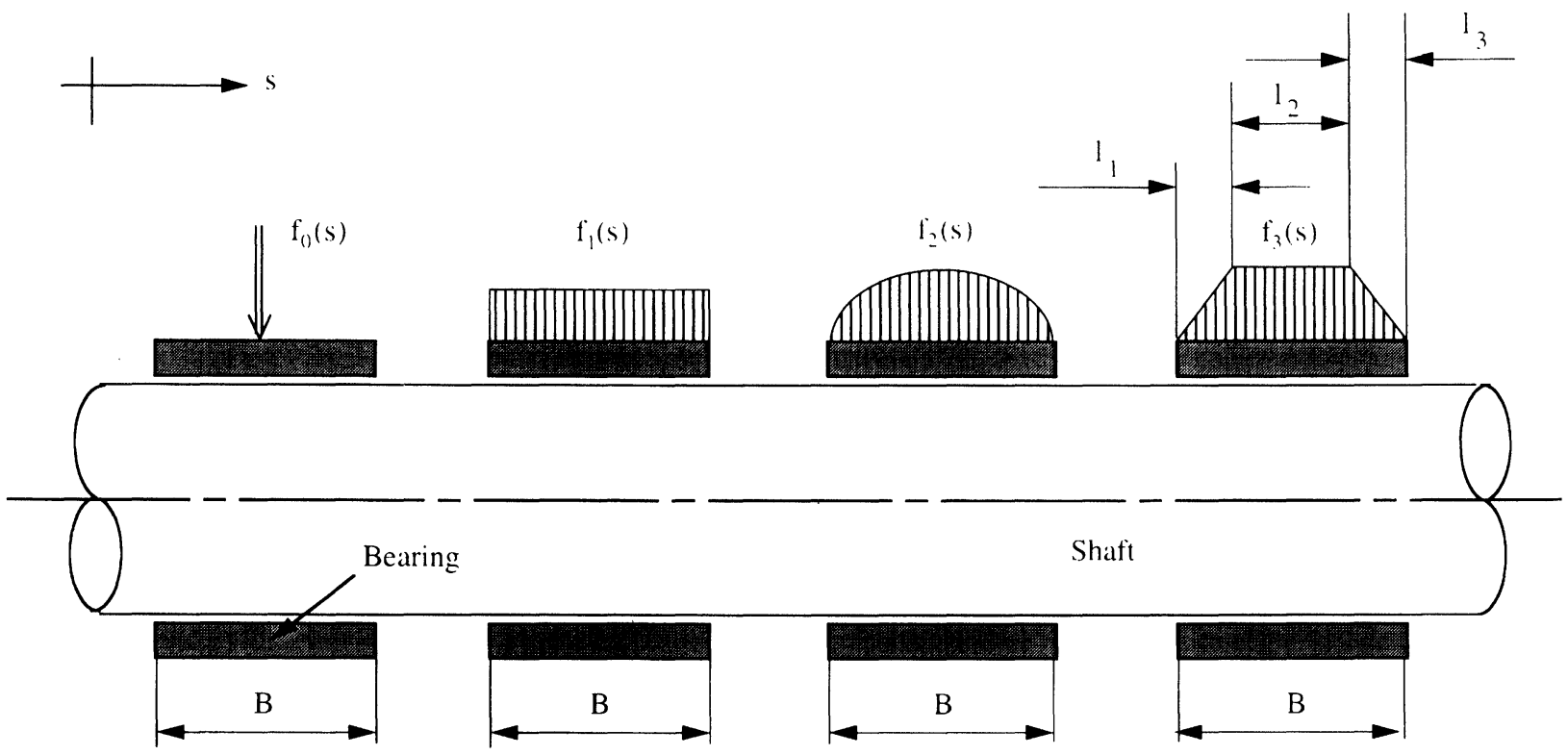

FIGURE 4 Approximated shape functions of rotor dynamic coefficients.

models is less than the point supported model. The uniformly distributed model is stiffer against rotation than other distributed models. So the natural frequencies of point supported and uniformly distributed models are overestimated from these results. Point supported and uniformly distributed models give similar results, and quadratically or trapezoidally distributed model gives similar results. (Some results are plotted as if they have same values.) So we can use alternative model for the vibration analysis. FIGURE 7 shows the difference ratio between point supported model and other models defined by

$$
\left|\frac{\omega_{\mathrm{P}}^{\mathrm{k}}-\omega_{\mathrm{j}}^{\mathrm{k}}}{\omega_{\mathrm{P}}^{\mathrm{k}}}\right| \times 100, \mathrm{j}=1,2,3
$$

where $\omega^{k}$ is the $k$-th natural frequency of the point supported model and $\omega^{\mathrm{k}}{ }_{\mathrm{i}}$ is the k-th natural frequency of other models. From these results it can be observed that the difference is considerable as the bearing length ratio is increased.

Similar calculations are carried out with varying the stiffness ratio of bearings for the bearing length ratio of 0.1 . From FIGUREs 8 and 9 it can be seen that differences between other models are increased as the bearing stiffness ratio is increased, but the difference ratio is almost independent of the bearing stiffness ratio except for the 1 st natural frequency of uniformly distributed model.

\section{Example 2}

We consider the rotor model which has three discs and supported by two cylindrical journal bearings as shown in FIGURE 10. The stability limit of the rotating speed is calculated for two types of support models, i.e., point supported model and quadratically distributed one. The results are shown in FIGURE 11. (The results of Glinicke et al. [1980] are used as the rotor-dynamic coefficients of the cylindrical journal bearings for some $\mathrm{B} / \mathrm{D}$ ratios. The data of the discs are shown in TABLE 2.)

From these results it is found that the stability limit of distributed model is lower than that of point supported one in the case of small $\mathrm{B} / \mathrm{D}$. The reason is that the logarithmic decrements of distributed model are smaller than those of point supported one.

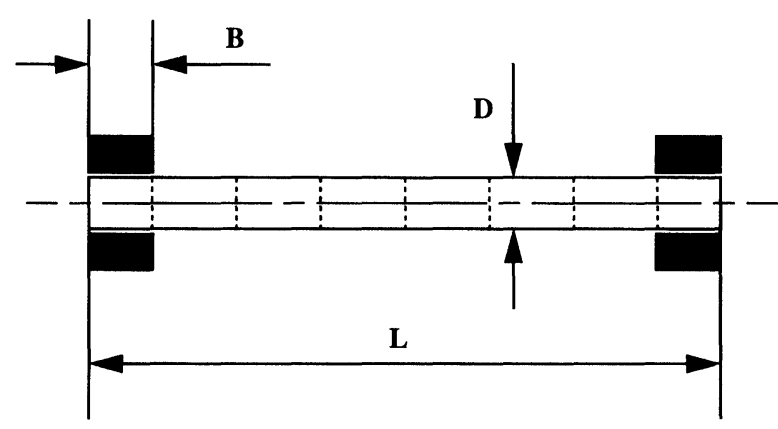

FIGURE 5 Simple rotor-bearing model. 


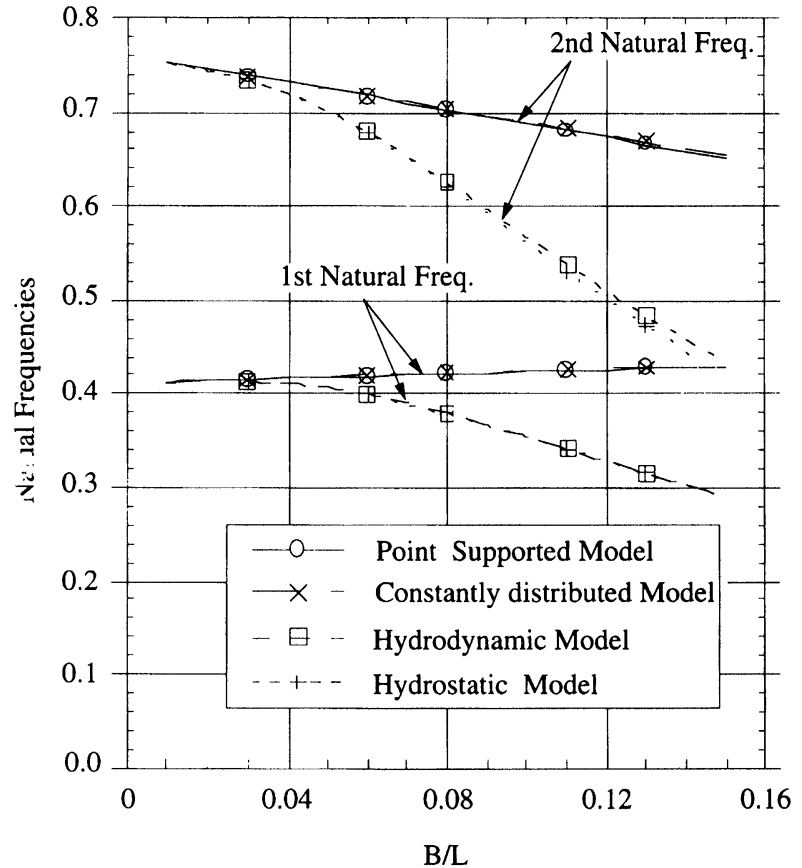

(a) Case 1

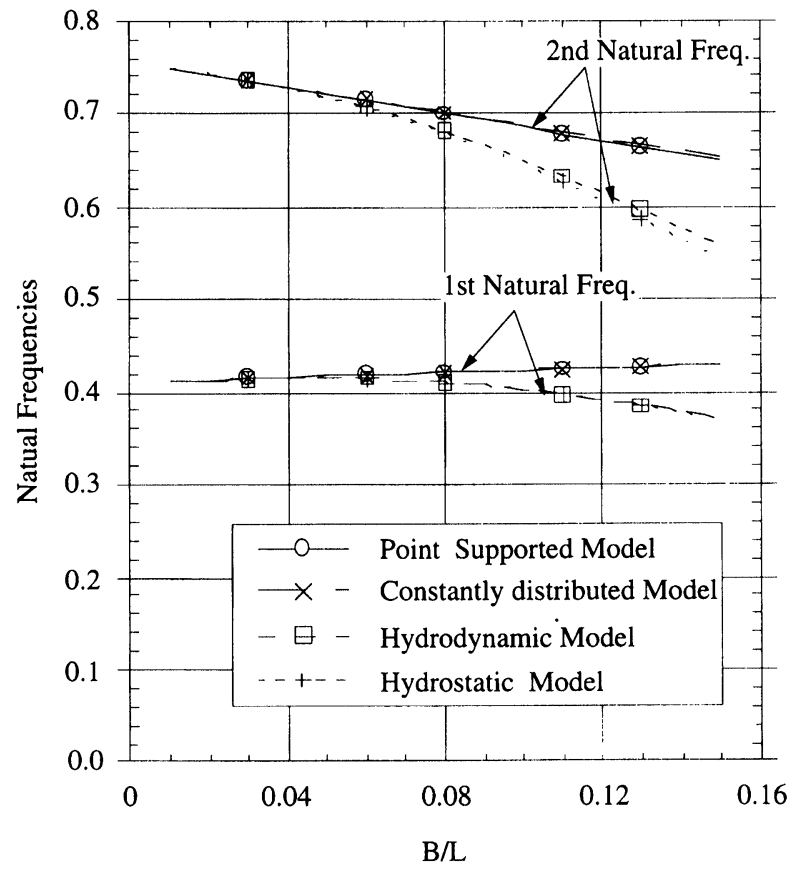

(b) Case 2

FIGURE 6 First two natural frequencies for some bearing length ratio.

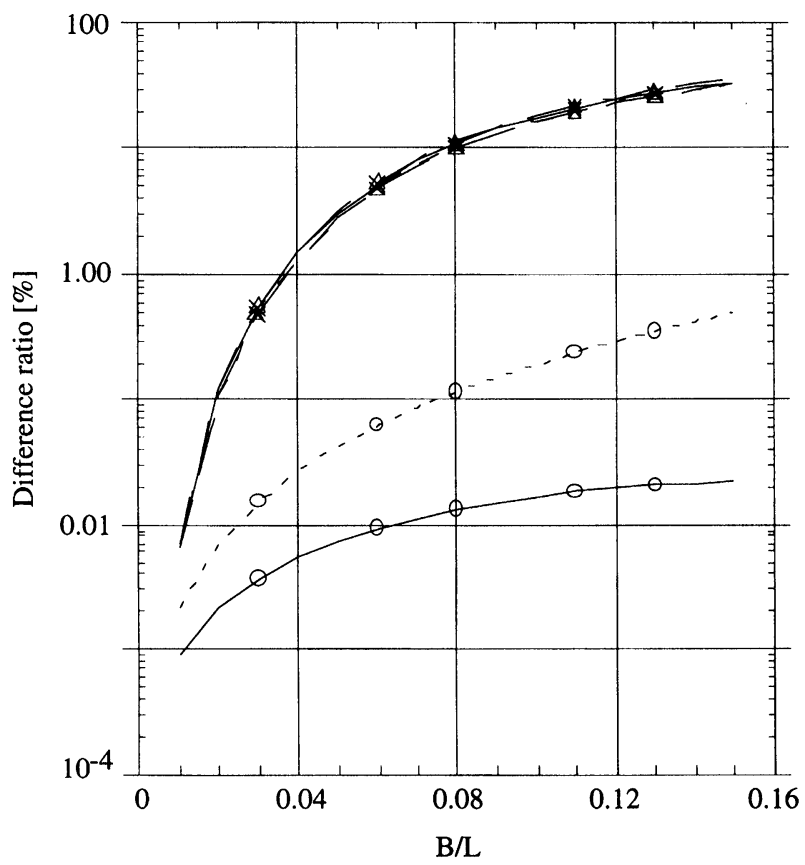

(a) Case 1

- 1 st Natural Freq. of Constantly distributed model

$\rightarrow-1$ st Natural Freq. of Hydrodynamic model

- $\Delta$ - 1st Natural Freq. of Hydrostatic model

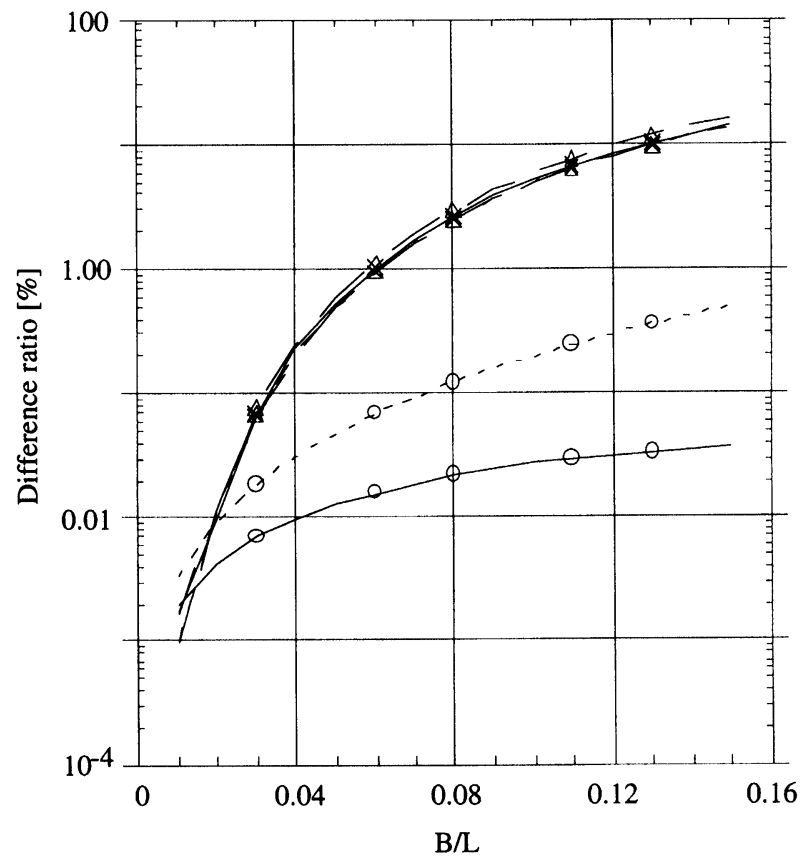

(b) Case 2

- - - - 2nd Natural Freq. of Constantly distributed model - - 2nd Natural Freq. of Hydrodynamic model

$\rightarrow$ - 2nd Natural Freq. of Hydrostatic model

FIGURE 7 Difference ratio of two models for some bearing length ratio. 


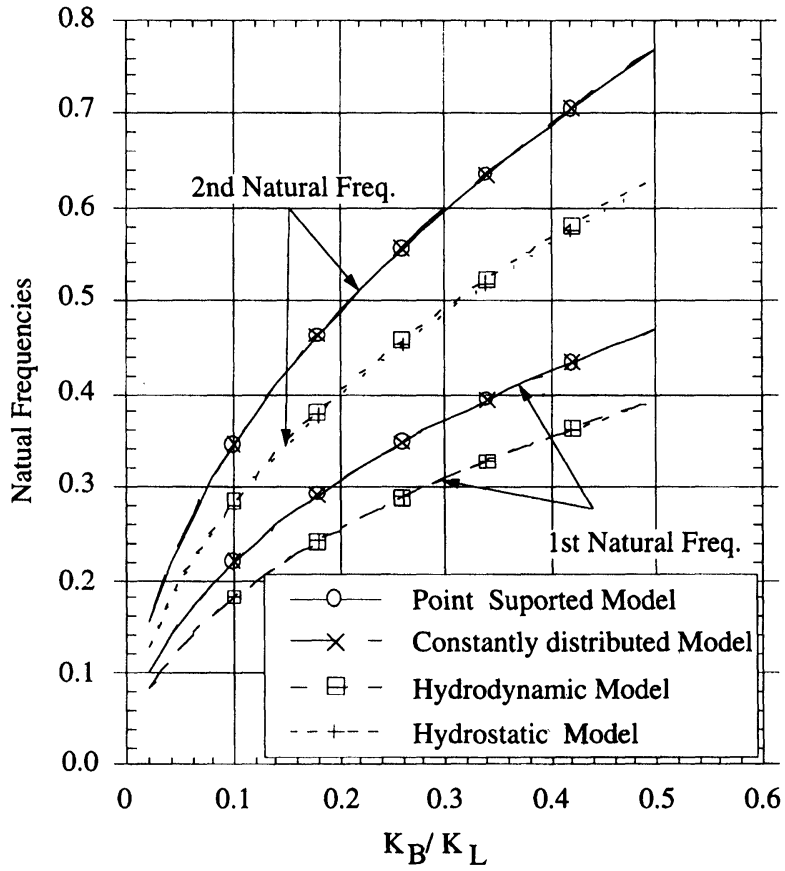

(a) Case 1

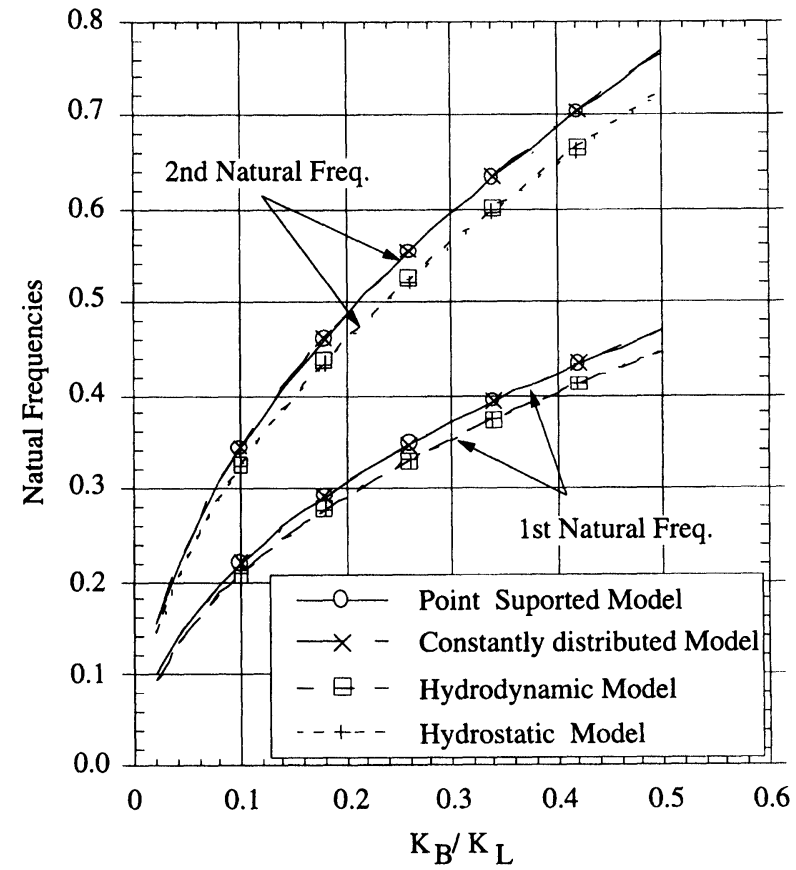

(b) Case 2

FIGURE 8 First two natural frequencies for some bearing stiffness ratio.

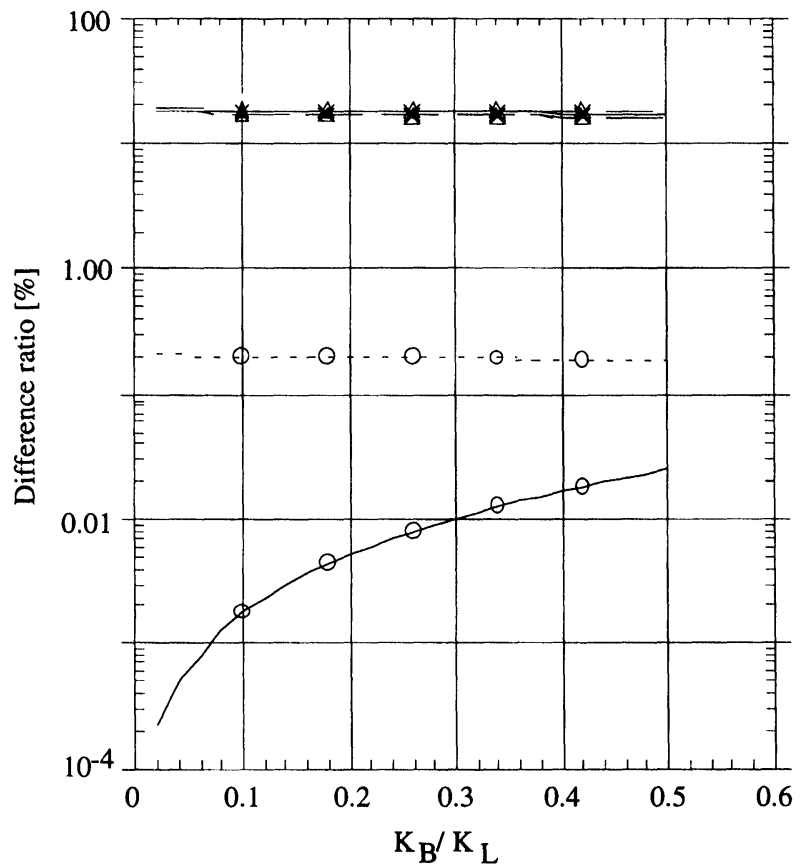

(a) Case 1

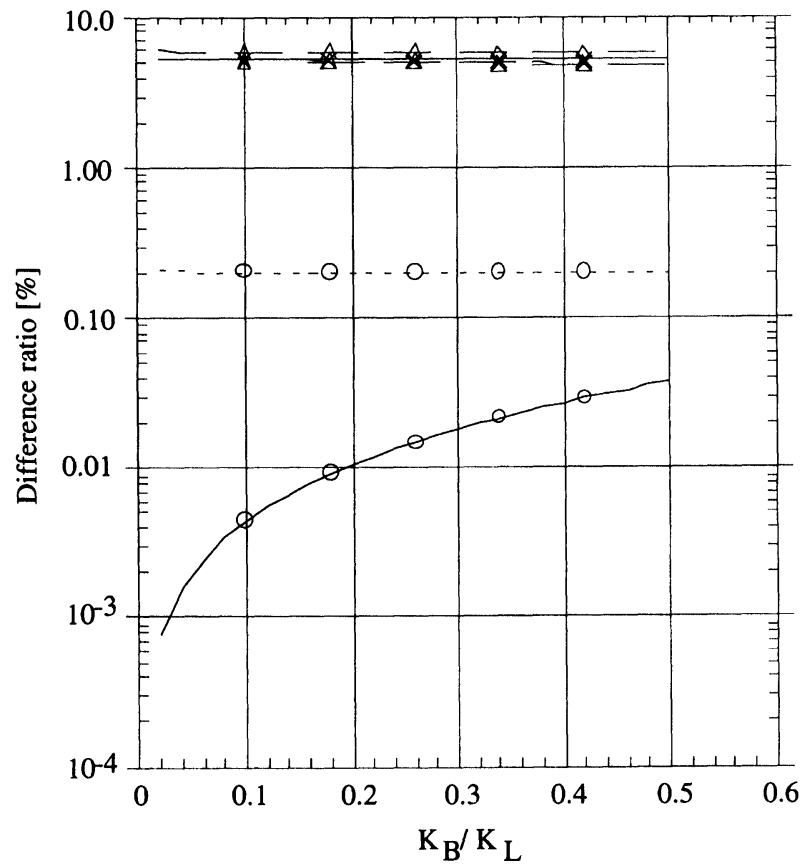

(b) Case 2

- - - 2nd Natural Freq. of Constantly distributed model

* 2nd Natural Freq. of Hydrodynamic model

$\triangle \quad$ 2nd Natural Freq. of Hydrostatic model

$\rightarrow-1$ st Natural Freq. of Hydrodynamic model

- $\Delta$ - 1st Natural Freq. of Hydrostatic model FIGURE 9 Difference ratio for some bearing stiffness ratio. 


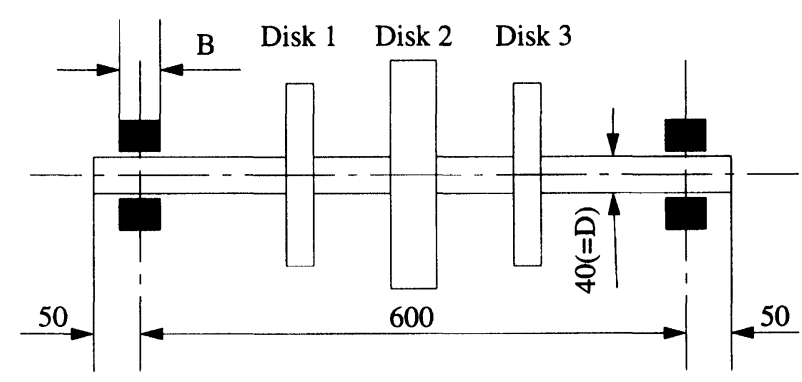

FIGURE 10 Rotor model for stability analysis.

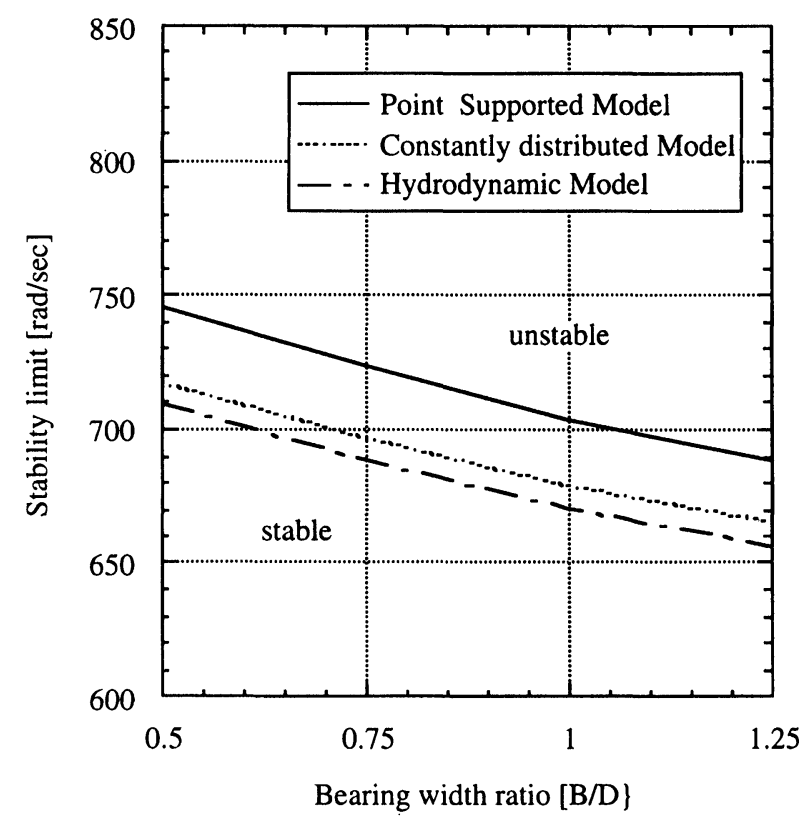

FIGURE 11 Stability limit of a example rotor.

TABLE 1

Data of the two example cases

\begin{tabular}{lcc}
\hline & Case 1 & Case 2 \\
$\mathrm{D} / \mathrm{L}$ & 0.03 & 0.05 \\
$\mathrm{E} / \mathrm{kG}$ & 2.81 & 2.81 \\
$\mathrm{~K}_{\mathrm{B}} / \mathrm{K}_{\mathrm{L}}$ & 0.4 & 0.4 \\
$\Omega / \omega_{0}$ & 0.02 & 0.02 \\
\hline
\end{tabular}

TABLE 2

Data of the discs

\begin{tabular}{lcc}
\hline & Disc 1 (= Disc 3) & Disc 2 \\
Outer Diameter & 200 & 250 \\
Inner Diameter & 40 & 40 \\
Width & 30 & 50 \\
\hline
\end{tabular}

\section{CONCLUSIONS}

The finite element approach is used in analyzing the influence of bearing width on the vibration characteristics of rotor-bearing systems where various models of bearing supports are used. It is suggested that hydrodynamic and hydrostatic journal bearings should be approximated by quadratically and trapezoidally distributed springs and dampers. Then, the first two natural frequencies of the uniform shaft, supported by two bearings, are calculated and compared for the point supported model, the uniformly distributed model and hydrostatically or hydrodynamically distributed model. And we calculate the stability limit of the simple rotor model supported by two cylindrical journal bearings. From this analysis, it is observed that the point supported or uniformly distributed bearing models overestimate the natural frequencies and the logarithmic decrements. So we should consider the effects of bearing width as the bearing length ratio, $\mathrm{B} / \mathrm{L}$, is increased.

However, in the present studies the bearing data are calculated on the assumption that the portion of the shaft in the bearing is rigid, so iterative method between flexible rotor analysis and bearing analysis will give more realistic results for a real rotor bearing system. (It is in progress.)

\section{Acknowlegements}

This research was carried out at the Turbo and Power Machinery Research Center and was funded by the Korea Science and Technology Engineering Foundation. Their supports are gracefully acknowledged.

\section{Nomenclature}

\begin{tabular}{|c|c|c|}
\hline$[\mathrm{M}],[\mathrm{C}],[\mathrm{G}],[\mathrm{K}]$ & $=$ & mass, damping, gyroscopic and stiffness \\
\hline$[\overline{\mathrm{M}}],[\overline{\mathrm{C}}],[\overline{\mathrm{G}}],[\overline{\mathrm{K}}]$ & $=$ & $\begin{array}{l}\text { nondimensional forms of mass, } \\
\text { damping, gyroscopic and stiffness } \\
\text { matrices }\end{array}$ \\
\hline [D] & $=$ & dynamic matrix \\
\hline$\{q\}$ & $=$ & displacement vector of the system. \\
\hline$(\mathrm{V}, \mathrm{W})$ & $=$ & $\begin{array}{l}\text { centerline displacement in }(\mathrm{Y}, \mathrm{Z}) \\
\text { directions }\end{array}$ \\
\hline$\{f\}$ & $=$ & force vector of the system \\
\hline$f_{i}$ & $=$ & $\begin{array}{l}\text { shape functions of bearing coefficients; } \\
i=0,1,2,3\end{array}$ \\
\hline$\Omega$ & $=$ & spin speed of shaft \\
\hline$\left[\mathrm{K}_{\mathrm{B}}^{\mathrm{e}}\right],\left[\mathrm{C}_{\mathrm{B}}^{\mathrm{e}}\right]$ & $=$ & $\begin{array}{l}\text { stiffness and damping matrices of } \\
\text { bearing part of finite shaft element }\end{array}$ \\
\hline$y, z$ & $=$ & $\begin{array}{l}\text { coordinates of horizontal and vertical } \\
\text { directions }\end{array}$ \\
\hline $\mathrm{k}_{\mathrm{ij}}, \mathrm{c}_{\mathrm{ij}}$ & $=$ & $\begin{array}{l}\text { shape function of bearing stiffness and } \\
\text { damping to the direction } i, j\end{array}$ \\
\hline
\end{tabular}




$\begin{array}{lll}\mathrm{K}_{\mathrm{ij}}, \mathrm{C}_{\mathrm{ij}} & = & \begin{array}{l}\text { the stiffness and the damping coefficient } \\ \text { of a bearing to the direction } \mathrm{i}, \mathrm{j}\end{array} \\ \mathrm{l} & = & \begin{array}{l}\text { length of finite shaft element } \\ \mathrm{B}\end{array} \\ \mathrm{L} & = & \text { bearing width } \\ \mathrm{EI} & = & \text { length of a shaft } \\ \mathrm{G} & = & \text { bending stiffness per unit curvature } \\ \mathrm{k} & = & \text { shear modulus } \\ \mathrm{K}_{\mathrm{B}} & = & \text { uncoupled stiffness of bearing } \\ \mathrm{K}_{\mathrm{L}}=48 \mathrm{EI} / \mathrm{L}^{3} & = & \text { stiffness of a simply suported beam } \\ \mathrm{m} & = & \text { mass per unit length shaft } \\ -(\text { bar) } & = & \text { nondimensional property }\end{array}$

\section{References}

Glienicke, J., D. C. Han. and M. Leonhard, 1980. Practical determination and use of bearing dynamic coefficients, Tribology international, Dec., pp. 297-309.

Gmür, T. C. and Rodrigues, J. D., 1991. Shaft Finite Elements for Rotor Dynamics Analysis, Transactions of ASME, Vol. 113, pp. 482-493.

Mourelatos, J. P. and Parsons, M. G., 1987. A Finite Element Analysis of Beams on Elastic Foundation including Shear and Axial Effects, Computers \& Structures, Vol. 27, No. 3, pp. 323-331.

Nelson, H. D., 1980. A Finite Rotating Shaft Element Using Timoshenko Beam Theory, Journal of Mechanical Design, Vol. 106, No. 4, pp. 793-803.

Özguven, H. N. and Özkan, Z. L., 1984. Whirl Speeds and Unbalance Response of Multibearing Rotors Using Finite Elements, Journal of Vibration, Acoustics, Stress and Reliability in Design, Vol. 106, No. 1, pp. 72-79.

Rouch, K. E. and Kao, J. S., 1979. A Tapered Beam Finite Element For Rotor Dynamics Analysis, Journal of Sound and Vibration, Vol. 66, No. 1, pp. 119-140.

\section{APPENDIX}

The shape function of the bearing coefficient.

$$
\begin{aligned}
& \mathrm{f}_{0}(\mathrm{~s})=\delta\left[\frac{\mathrm{B}}{2}\right] \\
& \mathrm{f}_{2}(\mathrm{~s})=6 \mathrm{~s}(1-\mathrm{s}) / \mathrm{L} \\
& \mathrm{f}_{1}(\mathrm{~s})=1 / \mathrm{L} \\
& \mathrm{f}_{3}(\mathrm{~s})=\frac{2}{1_{1}+21_{2}+1_{3}}\left\{\frac{\mathrm{s}}{1_{1}}[\mathrm{~s}]+\left[1-\frac{\mathrm{s}}{1_{1}}\right]\left[\mathrm{s}-1_{1}\right]+\right. \\
& \left.\left(-\mathrm{s}+1_{2}+1_{3}\right) / 1_{3}\left[\mathrm{~s}-1_{1}-1_{2}\right]\right\}
\end{aligned}
$$

where $[s]=1, \quad s \geq 0$

$$
[\mathrm{s}]=0, \quad \mathrm{~s}<0
$$

The shape function of the shaft.

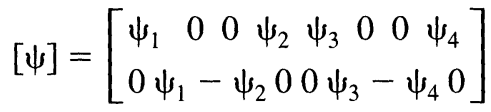

$$
\begin{aligned}
& \psi_{1}=\frac{1}{1+\Phi}\left[\alpha_{\mathrm{i}}+\Phi \beta_{\mathrm{i}}\right] \\
& \alpha_{1}=1-3 v^{2}+2 v^{3} \\
& \beta_{1}=1-v \\
& \alpha_{2}=1\left(v-2 v^{2}+v^{3}\right) \\
& \beta_{2}=\frac{1}{2}\left(v-v^{2}\right) \\
& \alpha_{3}=3 v^{2}-2 v^{3} \\
& \beta_{3}=v \\
& \alpha_{1}=1\left(-v^{2}+v^{3}\right) \\
& \beta_{4}=\frac{1}{2}\left(-v+v^{2}\right)
\end{aligned}
$$



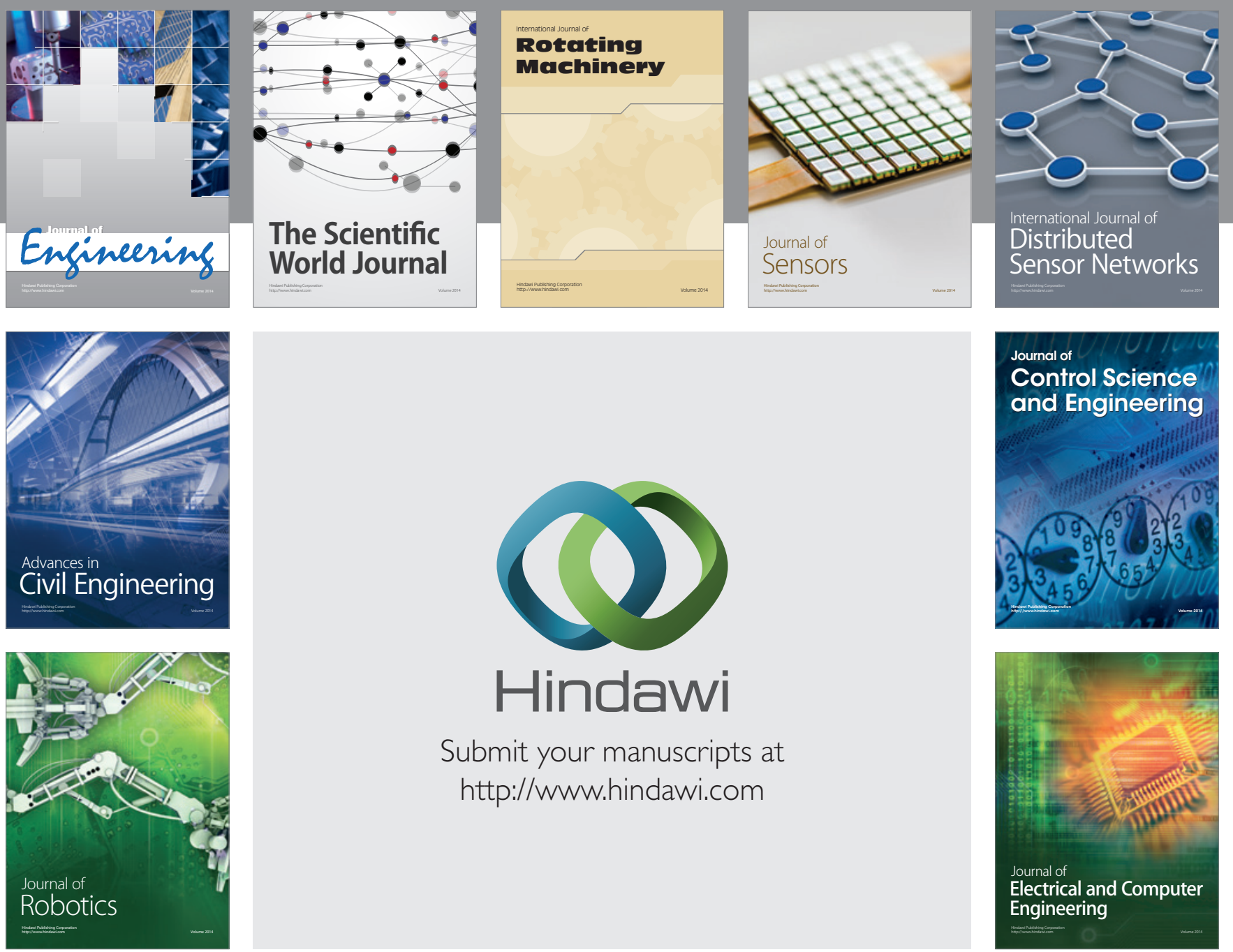

Submit your manuscripts at

http://www.hindawi.com
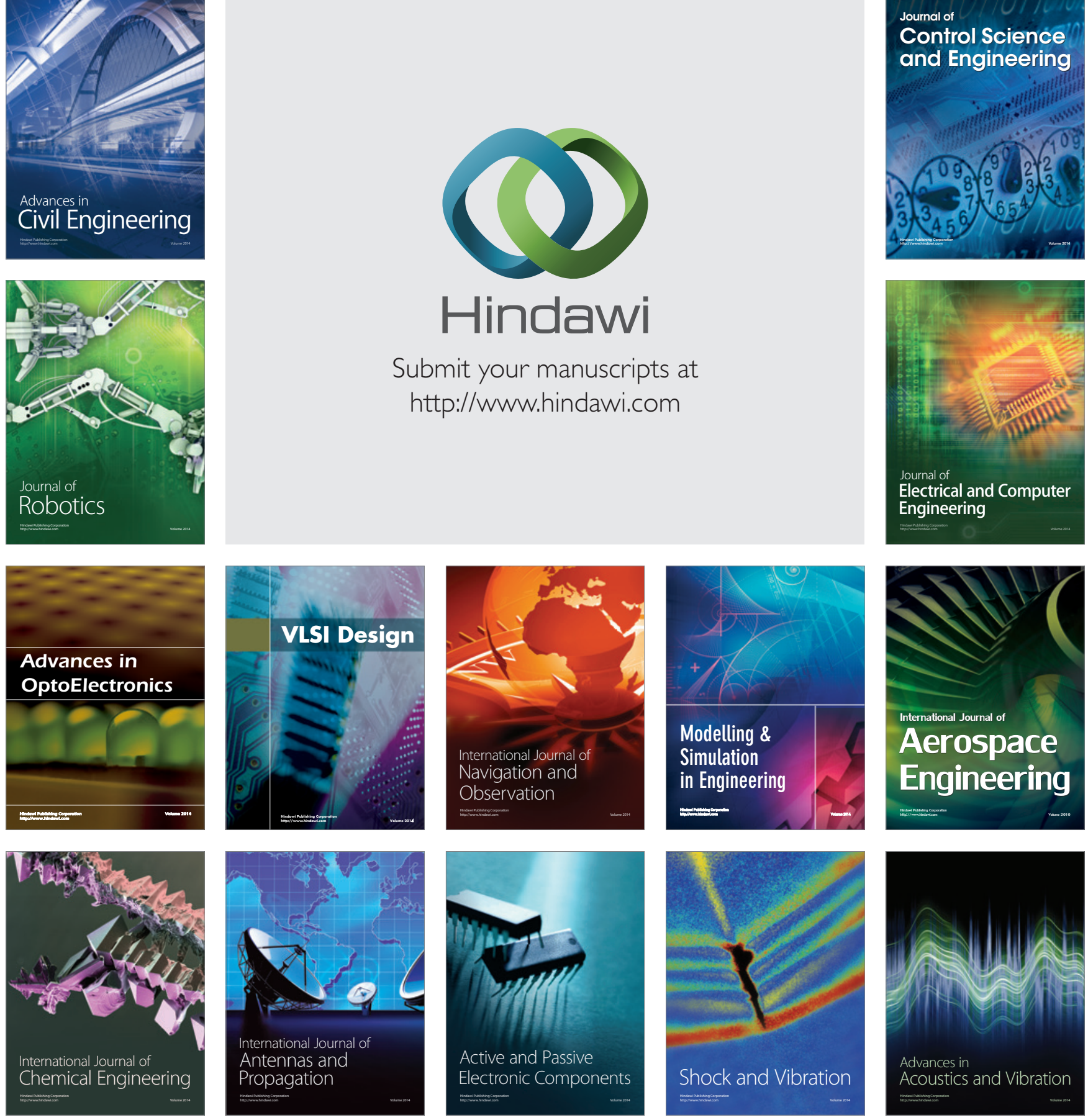